\title{
TREATMENT OF POSTOPERATIVE CEREBROSPINAL FLUID LEAKAGE BY BLOOD PATCH METHOD IN PATIENTS UNDERGOING VERTEBRA SURGERY
}

\author{
๑ Serkan Erman'1, ๑ Emre Bal², ๑ Firat Fidan ${ }^{3}$ \\ ${ }^{1}$ Sakarya University Training and Research Hospital, Clinic of Orthopedics and Traumatology, Sakarya, Turkey \\ ${ }^{2}$ Fatih Sultan Mehmet Training and Research Hospital, Clinic of Orthopedics and Traumatology, İstanbul, Turkey \\ ${ }^{3}$ Istanbul Aydın University Faculty of Medicine, Department of Orthopedics and Traumatology, Istanbul, Turkey
}

Objective: One of the complications in patients undergoing vertebra surgery is the prolonged cerebrospinal fluid (CSF) leakege due to incidental dura mater injury. Controlling this drainage is important in orthopedics practice with respect to vertebra surgery. Our aim was to investigate the effectiveness of widely used blood patch in the treatment of prolonged CSF leakage in patients undergoing vertebra surgery.

Materials and Methods: In this retrospective study, we reviewed medical records of patients who underwent vertebra surgery in our orthopedics and traumatology department. Among the 1385 patients examined, we included 64 of them who were performed blood patch and had $\geqslant 10$ days of CSF discharge postoperatively.

Results: In 64 of 1385 patients evaluated within the scope of the study, the results of patients who had CSF leakage for 10 days or more and were treated with blood patch were investigated. The distribution of operation site in patients who received blood patch showed that the most commonly involved site was lumbar site due to isolated lumbar surgery $(n=32)$. It was observed that the leakage stopped from the $1^{\text {st }}$ hour dressing in 4 of the patients, from the 6 th hour in 27 of them, and from the $24^{\text {th }}$ hour in 22 of them. Leakage in 5 patients stopped between day 1 and day 5 . The most common complication of the blood patch application in patients with $\geqslant 10$ days of CSF leakage was local low-back pain $(28.1 \%, \mathrm{n}=18)$.

Conclusion: The blood patch seems to be an effective, practical, cheap, and successful method with low rate of complications for reducing/ stopping prolonged CSF leakege after spine surgery.

Keywords: Blood patch, vertebra surgery, incidental dura injury, CSF leakage

\section{INTRODUCTION}

In spine surgery, cerebrospinal fluid (CSF) leakage after durotomy or secondary to incidental dura mater tears is a rare complication that could lead to serious consequences, requiring careful management. The incidental dura mater tears can vary greatly among surgeons, depending on the type and complexity of vertebra surgery procedures performed ${ }^{(1,2)}$.

In orthopedic practice of vertebra surgery, prolonged CSF leakage may be associated with headache, nausea, vomiting, dizziness, hypotension, infection, and intracranial or intraspinal complications ${ }^{(3,4)}$. Addressing this problem is important for both vertebra surgery clinics and patients' medical and mental disorders. These complications of prolonged CSF leakage, as in all complications of vertebra surgery, cause prolonged hospitalization with additional treatment costs. Prolonged CSF leakage can be managed with several methods, including a blood patch ${ }^{(5,6)}$.

Our aim was to investigate the effectiveness of blood patches in decreasing or ceasing postoperatively prolonged CSF leakage in patients undergoing vertebra surgery.

\section{MATERIALS AND METHODS}

This study was conducted in the orthopedics and traumatology clinic of the tertiary care hospital after the approval of the Non-Interventional Research Ethics Committee of Sakarya University with an approval number of: $715224730500104 / 32$. In this study, we retrospectively evaluated the medical records of 1385 patients who underwent vertebra surgery between January 2010 and August 2013. The patients in our study were found to read and give written consent about the blood patch procedure. 
We examined 232 patients with prolonged CSF leakage that was confirmed by clinical experience and biochemical tests. Sixty-four patients who had leakage for at least 10 days and did not respond to hydration and bed rest were included in the study. Data on these patients' medical history, physical examination, laboratory findings (blood and CSF), treatment regimens, complications, amount of fluid from the leakage with its clinical appearance, and blood patch treatment outcomes were collected. Magnetic resonance (MR) images obtained at postoperative first month was assessed for pseudomeningocele for patients who received blood patch.

All patients are administered the blood patch in the prone position under sterile conditions through the drain opening. If any local pain or radiculopathy occurs then the procedure was stopped, blood patch was never applied more than $30 \mathrm{~mL}$. After the application, the drainage tubes are removed, followed by tight dressing with abundant gauze sponge and pads under sterile conditions. Contaminated dressings are replaced immediately under sterile conditions. After the application of a blood patch, the prone position of the patient is maintained for 20-30 minutes under direct observation of a healthcare staff to monitor the general condition and check vital signs every 10 minutes. All patients are then instructed to be mobile as much as possible during the day. After the application, the dressing control of the patients was performed at the $1^{\text {st }}, 6^{\text {th }}$ and $24^{\text {th }}$ hours. After the $24^{\text {th }}$ hour, daily wound dressing control was performed. Waited 5 days to pass between repeated blood patches. If repeated blood patch application is required, the procedure was performed by the epidural needle to the likely area under scope guidance

\section{RESULTS}

In 64 of 1385 patients evaluated within the scope of the study, the results of patients who had CSF leakage for 10 days or more and were treated with blood patch were investigated. In this study, when the distribution of patients who underwent spinal surgery was examined by gender, it was seen that 596 (43\%) of the patients were male and 789 (57\%) were female. Considering the age distribution of these patients, it was found that the mean age for men was 34.2, while the mean age for women was 32.4. Twenty-seven (42.1\%) patients were male and 37 (57.9\%) were females who underwent blood patch.

The distribution of operation site in patients who received blood patch showed that the most commonly involved site was isolated lumbar surgery $(n=32)$, followed by thoracolumbar surgery $(n=23)$ and thoracic surgery $(n=9)$. No blood patch treatment was applied to any patient who had cervical surgery (Figure 1).

It was found that all patients treated with blood patch underwent laminectomy. The most frequently performed procedure in these patients was posterior spinal instrumentation (PSI) + laminectomy + cage insertion $(n=28)$, followed by PSI + laminectomy + pedicule subtraction osteotomy $(n=20)$, PSI + laminectomy $(n=11)$, and laminectomy alone $(n=5)$ (Table 1$)$. It was observed that the leakage stopped from the $1^{\text {st-hour }}$ dressing in 4 of the patients, from the $6^{\text {th }}$ hour in 27 of them, and from the $24^{\text {th }}$ hour in 22 of them leakage of 5 patients had stopped between day 1 and day 5 . After continued to leakage on day 5 , a second blood patch was applied in six patients. In the first 24 hours after the second application, leakage stopped in 4 patients. Leakage stopped 48 hours after the second application in 1 patient, and 96 hours after the second application in 1 patient.

The most common complication of the blood patch application in patients with $\geqslant 10$ days of CSF leakage was local lowback pain $(28.1 \%, n=18)$. Fifteen patients were found to have nausea/vomiting, relieved with slowing or interrupting the blood patch administration followed by serum physiologic infusion and close monitoring. Twelve (18.7\%) patients were detected to have dizziness and hypotensive episode, resolved by normalized blood pressure levels within ten minutes after serum physiologic infusion. As a delayed complication, four patients had pseudomeningocele, confirmed by clinical and MR imaging findings (Figure 2).

\section{DISCUSSION}

Incidental dura mater injuries are one of the important complications of vertebra surgery with an incidence rate of $1 \%$ to $14 \%^{(7-9)}$. Risk factors reported in dura injury include advanced age, anatomical spine variations, revision surgery, thin and weak dura layer, and surgeons with little or no experience ${ }^{(10)}$.

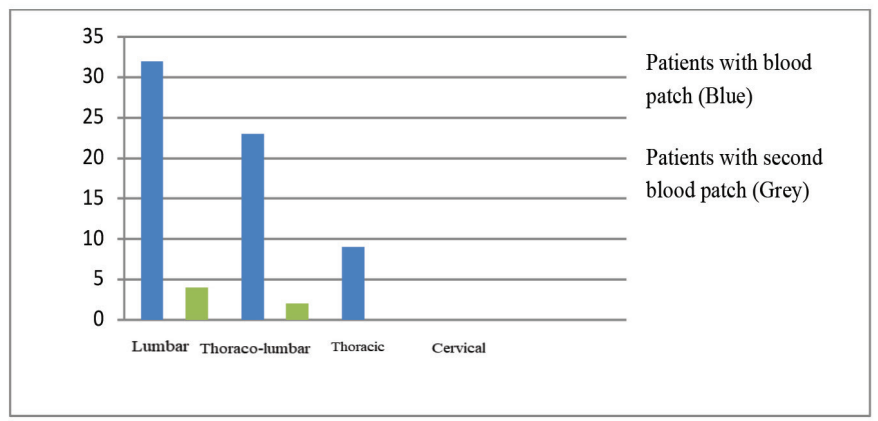

Figure 1. Blood patch application by spinal levels

Table 1. Distribution of surgical interventions in patients who were applied blood patch

\begin{tabular}{ll}
\hline Surgical procedure & Patients, $n$ \\
\hline PSI + Laminectomy + Cage insertion & 28 \\
\hline PSI + Laminectomy + PSO & 20 \\
\hline PSI + Laminectomy & 11 \\
Laminectomy & 5 \\
\hline Total & 64 \\
\hline PSI: Posterior spinal instrumentation, PSO: Pedicle subtraction \\
osteotomy
\end{tabular}




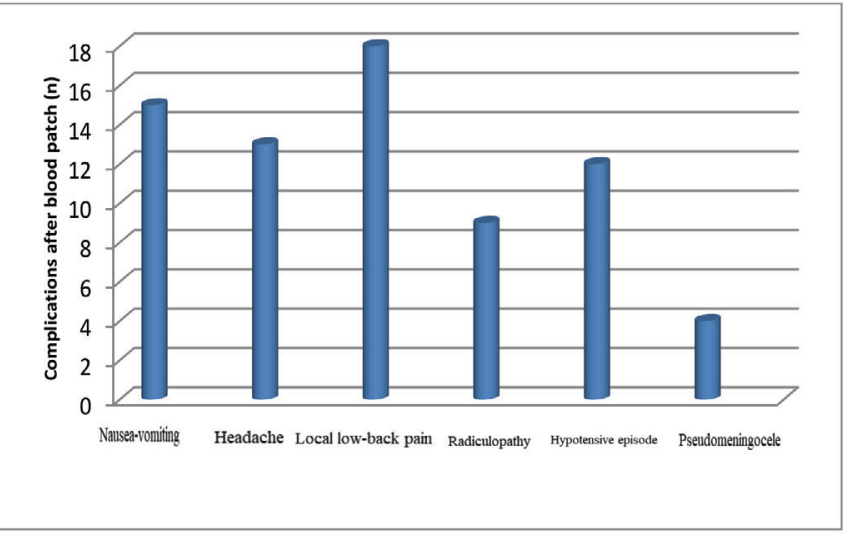

Figure 2. Complications after blood patch application

Dura tears are mostly formed in patients with adherent dura tissue, poorly planned dissections, altered anatomy, subsequently developing scar tissue, and first surgery. Since a small incision and split muscle incision reduce the potentially dead space, this approach is less likely to create persistent CSF leakage that may occur after durotomy. Spinal instrumentation creates more dead space around the dura, preventing the buffering effect of the paraspinal muscles on the dura tears. Persistent CSF leaking through the subarachnoid space causes signs and symptoms associated with dura mater tears. Persistent CSF leak may lead to cranial nerve palsy, radiculopathy-related chronic pain, and postural headache. Pseudomeningocele and cerebrospinal fistula can be seen postoperatively ${ }^{(11)}$.

In the past, the CSF leakage that occurred after vertebra surgery was treated with surgical dura repair. Recently, dural materials and adhesives have been used as useful methods for dura repair. As an alternative to surgical modalities, closed subarachnoid drainage was also recommended(11).

Epidural (autologous) blood patch was first used by Gormley(12) in the treatment of headache that occurred as a result of dural puncture after spinal anesthesia in 1960. This procedure is mostly used in the treatment of headaches in patients who do not respond to conservative treatment (hydration, bed rest, pain relief medication) in anesthesiology practice. Animal and laboratory studies reported that autologous blood injection into the epidural space created blood clots in approximately 30 seconds and reduced CSF leakage ${ }^{(13)}$. Recently, this procedure has been reported to be used in the treatment of spontaneous low CSF pressure headache and in the treatment of CSF leakage in several patients (3 lumbar cases, 1 thoracic case) who underwent vertebra surgery. In the literature, bed rest for 24 to 96 hours has been recommended for patients with CSF leakage after vertebra surgery ${ }^{(14)}$. Tosun et al. ${ }^{(11)}$ suggested bed rest of 48-96 hours for their patients with persistent CSF leakage after thoracolumbar vertebra surgery. In our cases, bed rest was recommended for 24-48 hours. After an epidural blood patch application, there is no need for general anesthesia and surgical re-exploration. At the same time, the clinicians have the opportunity to observe whether the CSF leakage would continue. According to previous studies infection risk is low ${ }^{(14)}$.

Epidural blood patch may also be associated with several complications such as low-back pain and stiffness, radicular nerve discomfort, and subdural hematoma. Although hematoma-induced dural sac compression may occur, there is no paraplegia reported in the literature. However, surgical dura repair may be performed in rare cases where decompression is required or paraplegia occurs secondary to blood patch, or CSF leakage does not cease despite blood patch ${ }^{(14-17)}$. Than et al. (18) have recently reported successful outcomes in the management of incidental durotomy, where they treated five patients with minimal primary repair surgery.

Since the blood patch is introduced from where the leakage came from, there is a high probability that it will reach the level of the dura mater rupture with the leak. Therefore, it is much more effective in stopping CSF leakage. Compared to the blood patch applications via the injector, the method applied from the drainage tube is easy to apply and its complications such as incorrectly applied site, inability to apply adequate blood patch, dura mater injury, radiculopathy are much less. Studies reported that blood patches performed through epidural needles are effective up to about nine spinal levels ${ }^{(7)}$.

The literature regarding the treatment of dura tears shows many modalities including medical treatment accompanied with bed rest, primary repair, closed subarachnoid drainage, muscle fat or fascia containing grafts, fibrin adhesives, cyanoacrylate polymer filler, gel foam application to the tear site, saline solution, dextrose solution infusion, and blood patch application ${ }^{(5-17)}$. Ylönen and Kokki ${ }^{(19)}$ reported a successful outcome in their study of 40 patients; where $93 \%$ of patients responded after the first blood patch, and the remaining $\% 7$ achieved a positive outcome after the second blood patch.

In patients who develop prolonged CSF leakage after vertebra surgery, if the leakage continues despite conservative treatment, autologous blood patch is one of the treatment methods that should be considered.

\section{Study Limitations}

The limitations of our article are the lack of a comparison group and the small number of patients.

\section{CONCLUSION}

In patients undergoing vertebra surgery, prolonged CSF leakage after incidental dura mater injury may create a predisposition for many complications, have a negative impact on the patient's psychological status, and increase hospital expenditures during the prolonged length of stay.

In conclusion, the blood patch seems to be an effective, practical, cheap, and successful method with low rate of complications for reducing/stopping prolonged CSF leakage in patients who underwent vertebra surgery. 


\section{Ethics}

Ethics Committee Approval: This study was approved of the Non-Interventional Research Ethics Committee of Sakarya University with an approval number of: 715224730500104/32. Informed Consent: The patients in our study were found to read and give written consent about blood patch procedure.

Peer-review: Internally peer-reviewed.

\section{Authorship Contributions}

Surgical and Medical Practices: S.E., E.B., F.F., Design: S.E., E.B., F.F., Data Collection or Processing: S.E., E.B., F.F., Analysis or Interpretation: S.E., E.B., F.F., Literature Search: S.E., E.B., F.F., Writing: S.E., E.B., F.F.

Financial Disclosure: The authors declared that this study received no financial support.

Conflict of Interest: The authors have no conflicts of interest to declare.

\section{REFERENCES}

1. Hughes SA, Ozgur BM, German M, Taylor WR. Prolonged JacksonPratt drainage in the management of lumbar cerebrospinal fluid leaks. Surg Neurol. 2006;65:410-4.

2. Borgesen SE, Vang PS. Extradural pseudocysts: a cause of pain after lumbar-disc operation. Acta Orthop Scand. 1973;44:12-20.

3. Bosacco SI, Gardner MI, Guille IT. Evaluation and treatment of dural tears in lumbar spine surgery: a review. Clin Orthop Relat Res. 2001;389:238-47.

4. Patel MR, Louie W, Rachlin J. Postoperative cerebrospinal fluid leaks of the lumbosacral spine: management with percutaneous fibrin glue. AJNR Am J Neuroradiol. 1996; 17:495-500.

5. Jones AA, Stambough JL, Balderston RA, Rothman RH, Booth RE Jr. Long-term results of lumbar spine surgery complicated by unintended incidental durotomy. Spine (Phila Pa 1976). 1989;14:443-6.

6. Eismont FJ, Wiesel SW, Rothman RH. Treatment of dural tears associated with vertebra surgery. J Bone Joint Surg Am. 1981;63:1132-6.
7. Oedit R, van Kooten F, Bakker SL, Dippel DW. Efficacy of the epidural blood patch for the treatment of post lumbar puncture headache BLOPP: a randomised, observer-blind, controlled clinical trial [ISRCTN 71598245]. BMC Neurol. 2005;5:12.

8. Wang JC, Bohlman HH, Riew KD. Dural tears secondary to operations on the lumbar spine. Management and results after a two-yearminimum follow-up of eighty-eight patients. J Bone Joint Surg Am. 1998;80:1728-32.

9. Hannallah D, Lee J, Khan M, Donaldson WF, Kang JD. Cerebrospinal fluid leaks following cervical spine surgery. J Bone Joint Surg Am. 2008;90:1101-5.

10. Baker GA, Cizik AM, Bransford RJ, Bellabarba C, Konodi MA, Chapman $J R$, et al. Risk factors for unintended durotomy during spine surgery: a multivariate analysis. Spine J. 2012;12:121-6.

11. Tosun B, Ilbay K, Kim MS, Selek O. Management of persistent cerebrospinal fluid leakage following thoraco-lumbar surgery. Asian Spine J. 2012;6:157-62.

12. Gormley JB. Treatment of postspinal headache. Anesthesiology 1960;21:545-6.

13. Abouleish E, Vega S, Blendinger I, Tio TO. Long-term follow-up of epidural blood patch. Anesth Analg. 1975; 54:459-63.

14. Lauer KK, Haddox JD. Epidural blood patch as treatment for a surgical durocutaneous fistula. J Clin Anesth. 1992;4:45-7.

15. Mino M, Narita N, Adachi M. [Epidural blood patch for the treatment of intracranial hypotension due to cerebrospinal fluid leakage after thoracic spine surgery]. No Shinkei Geka. 2001;29:865-9. (Japanese)

16. Eismont FJ, Wiesel SW, Rothman RH. Treatment of dural tears associated with vertebra surgery. J Bone Joint Surg Am. 1981;63:1132-6.

17. Jankowitz BT, Atteberry DS, Gerszten PC, Karausky P, Cheng BC, Faught $\mathrm{R}$, et al. Effect of fibrin glue on the prevention of persistent cerebral spinal fluid leakage after incidental durotomy during lumbar vertebra surgery. Eur Spine J 2009;18:1169-74.

18. Than KD, Wang AC, Etame AB, La Marca F, Park P. Postoperative management of incidental durotomy in minimally invasive lumbar spinal surgery. Minim Invasive Neurosurg. 2008;51:263-6.

19. Ylönen P, Kokki H. Epidural blood patch for management of postdural puncture headache in adolescents. Acta Anaesthesiol Scand. 2002; 46:794-8. 